\title{
Effectiveness of multicomponent lower extremity injury prevention programmes in team-sport athletes: an umbrella review
}

\author{
Romana Brunner, ${ }^{1}$ Bernd Friesenbichler, ${ }^{1}$ Nicola C Casartelli, ${ }^{1,2}$ Mario Bizzini, ${ }^{1}$ \\ Nicola A Maffiuletti, ${ }^{1}$ Karin Niedermann ${ }^{3}$
}

\begin{abstract}
- Additional material is published online only. To view please visit the journal online (http://dx.doi.org/10.1136/ bjsports-2017-098944)

${ }^{1}$ Human Performance Lab, Schulthess Clinic, Zurich, Switzerland

${ }^{2}$ Laboratory of Exercise and Health, Department of Health Sciences and Technology, ETH Zurich, Zurich, Switzerland ${ }^{3}$ Institute of Physiotherapy, School of Health Professions, Zurich University of Applied Sciences, Winterthur,

Switzerland
\end{abstract}

\section{Correspondence to}

Romana Brunner, Human Performance Lab, Schulthess Clinic, Zurich $\mathrm{CH}-8008$, Switzerland; romana.brunner@kws.ch

Accepted 9 August 2018 Published Online First 10 September 2018

\section{Check for updates}

(C) Author(s) (or their employer(s)) 2019. No commercial re-use. See rights and permissions. Published by BMJ.

\section{To cite: Brunner $\mathrm{R}$,} Friesenbichler $B$

Casartelli NC, et al.

$\mathrm{Br} J$ Sports Med

2019:53:282-288

\section{ABSTRACT}

Objective To identify which exercise combinations are most effective as part of a lower extremity injury prevention programme for team-sport athletes.

Design Umbrella review.

Data sources A comprehensive literature search was performed in PubMed, Scopus, Cochrane Library and PEDro databases. Studies published between January 2000 and March 2017 were included in this umbrella review.

Study eligibility criteria Moderate to high-quality systematic reviews that investigated the effectiveness of a combination of two or more exercise components, that is, strength, agility, plyometrics, balance, stretching, technique, warm-up and functional activity, regarding injury incidence/rate of lower extremity injuries in team-sport athletes. The methodological quality of the included systematic reviews was independently assessed by two reviewers using the Assessing the Methodological Quality of Systematic Reviews measurement tool and the Grading of Recommendations Assessment, Development and Evaluation guidelines were used to assess the overall quality of evidence for particular outcomes.

Results Twenty-four systematic reviews met the inclusion criteria. Multicomponent exercise interventions were effective in reducing the injury incidence/rate of lower extremity, knee, ACL and ankle injuries, but not groin injuries. Strength and balance exercise components were included in 10 of 11 effective injury prevention programmes for the lower extremity, knee, $A C L$ and ankle injuries.

Summary/conclusion Lower extremity injury prevention programmes in team sports are effective in preventing lower extremity, knee, $\mathrm{ACL}$ and ankle injuries. Lower extremity muscle strength and balance exercises should be prioritised in lower extremity injury prevention programmes for team-sport athletes.

\section{INTRODUCTION}

An average of 8.6 million sports-related injuries were documented per year between 2011 and 2014 in the USA, which equates to an incidence rate of 34 injuries per 1000 persons. ${ }^{1}$ The majority of these injuries were lower extremity strains and sprains sustained during basketball, American football and soccer (42\%). ${ }^{1}$ A similar rate of 26 injuries per 1000 persons was calculated for the European Union, with a peak occurring in the 15-19years age group. ${ }^{2}$ The most common traumatic injuries in team ball sports, such as basketball, volleyball, soccer and field hockey, are ligament injuries of the ankle (15\% of all reported sports injuries), followed by the knee $(3 \%$ of all reported sports injuries), ${ }^{34}$ whereas overuse injuries mostly affect the groin area ${ }^{5}$ and represent $5 \%-10 \%$ of all sports-related injuries.

Injury risk factors may have intrinsic (eg, age, sex, general health, physical fitness) and extrinsic (eg, sports venue, equipment and environmental) origins. ${ }^{7}$ The risk for injuries associated with these intrinsic and extrinsic risk factors can be reduced if athletes complete specific exercise programmes. ${ }^{9-16}$ Previous systematic reviews have focused on evaluating the effectiveness of single exercise components (eg, balance) or combinations of two or more exercise components (eg, strength, agility, plyometrics and stretching); however, injury prevention programmes including balance training as a single-component exercise did not reduce the incidence of knee ligament injuries. ${ }^{10} 14$ Similarly, stretching did not reduce the incidence of lower extremity sports injuries. ${ }^{17}$

Injury prevention should be a primary goal for team-sport athletes of all ages and participation levels (eg, recreational, semiprofessional, professional) since an injury results in performance disability, loss of playing time, high financial burden for the athlete's employer as well as the healthcare system and an increased risk of reinjury and chronicity. ${ }^{6}$ However, it remains unclear which combinations of exercise components are most effective in preventing lower extremity injuries. To identify the most effective exercise combinations, high-level synthesis of the available data, in the form of an umbrella review, is necessary. ${ }^{18}$

The objective of our umbrella review was to identify the most effective combinations of exercise elements for training programmes to prevent lower extremity injuries in team-sport athletes.

\section{METHODS}

This umbrella review was performed according to guidelines established by the working group of Aromataris et al. ${ }^{19}$ The study is registered in the International Prospective Register of Systematic Reviews (PROSPERO ID CRD42016041667).

\section{Inclusion criteria}

We applied the Assessing the Methodological Quality of Systematic Reviews (AMSTAR) rating system to rate and classify all reviews into low quality (scores of 0 to $\leq 3$ points), moderate quality ( 3 to $\leq 7$ ) and high quality $(7$ to $\leq 11) .{ }^{20}$ Only moderate and 
high-quality reviews were included. Reviews were included if published in either English or German between 1 January 2000 and 31 March 2017. The following inclusion criteria were considered according to the Participant-Intervention-Comparison-Outcome process for evidence-based practice. ${ }^{21}$

\section{Participants}

Male and/or female athletes of all ages who participated in team sports at any level (ie, recreational, semiprofessional, professional).

\section{Interventions}

All types of multicomponent exercise interventions to prevent lower extremity injuries. Interventions using protective devices (ie, braces, tapes) or exercise programmes including only one exercise component were excluded (eg, injury prevention programmes using eccentric strength exercises only to prevent hamstring injuries).

\section{Comparison group}

Usual training (no additional training).

\section{Outcome measures}

Injury incidence or injury rate.

\section{Search strategy}

A systematic literature search was performed by one reviewer (RB) in the following electronic databases: PubMed, Scopus, Cochrane Library (Cochrane Database of Systematic Reviews) and Physiotherapy Evidence Database (PEDro). The following search terms were used for PubMed: (athlete OR sportsman OR sportswoman OR sport) AND (prevention OR intervention OR prophylaxis OR avoidance) AND (sport injury OR athletic injury OR sport accident OR sport trauma). Search terms for the Scopus and Cochrane Library databases were: ('injury prevention' AND athlete OR sport). For the PEDro database, the following advanced search for systematic reviews was conducted: (injur* prevent* sport*). An expert in the field of preventive sports medicine (MB) identified through citation tracking any missing but relevant studies on the topic. Duplicates were identified and removed by one reviewer (RB).

Two reviewers (RB and NCC) then independently screened the titles and abstracts of all retrieved studies, and determined the eligibility of the potentially relevant full-text articles. If the decision of eligibility differed, a third reviewer was consulted (NAM) to evaluate the identified articles and reach final consensus on the inclusion of selected articles.

\section{Methodological quality evaluation}

Two reviewers (RB and $\mathrm{KN}$ ) independently assessed the methodological quality of the included systematic reviews using the AMSTAR tool. If the assessment was unclear, consensus was either reached by discussion or with the help of a third reviewer (NAM). The AMSTAR checklist is a reliable and valid instrument, which assesses the risk of systematic review bias. ${ }^{22}$ It comprises 11 different domains that are answered with the following options: 'yes'; 'no'; 'cannot answer'; and 'not applicable'; only a 'yes' answer is nominated with a score of 1 point.

To assess the overall quality of evidence of all included systematic reviews, we applied an adapted form of the Grading of Recommendations Assessment, Development and Evaluation (GRADE) principles. ${ }^{23}$ There are five GRADE categories: high; moderate; low; very low; and no evidence from systematic
Table 1 Description of study outcomes and exercise elements

\begin{tabular}{|c|c|}
\hline Study outcomes & Description \\
\hline Lower extremity injuries & Lower limb injuries, all sports injuries, all injuries \\
\hline Groin injuries & Groin injuries \\
\hline Knee injuries & $\begin{array}{l}\text { Knee joint injuries, acute knee injuries, undefined knee } \\
\text { injuries }\end{array}$ \\
\hline $\mathrm{ACL}$ injuries & $\mathrm{ACL}$ injuries, non-contact $\mathrm{ACL}$ injuries \\
\hline Ankle injuries & $\begin{array}{l}\text { Acute ankle injuries, ankle sprains, undefined ankle } \\
\text { injuries }\end{array}$ \\
\hline \multicolumn{2}{|l|}{ Exercise elements } \\
\hline Strength & $\begin{array}{l}\text { Eccentric or concentric strength training, weight training, } \\
\text { core stability or power training }\end{array}$ \\
\hline Agility & $\begin{array}{l}\text { Sport cord drills, sports-specific drills or running } \\
\text { techniques }\end{array}$ \\
\hline Plyometric & Jumping and rebounding exercises \\
\hline Balance & $\begin{array}{l}\text { Proprioception, neuromuscular training with wobble } \\
\text { boards or balance mats, dynamic stability, body control or } \\
\text { one-leg coordination }\end{array}$ \\
\hline Stretching & Flexibility exercises \\
\hline Technique & $\begin{array}{l}\text { Single-leg jumps with focus on leg alignment, jumping } \\
\text { and landing techniques, and neuromuscular control during } \\
\text { landing manoeuvers }\end{array}$ \\
\hline Warm-up & $\begin{array}{l}\text { Aerobic exercises, muscle activation or unspecified basic } \\
\text { warm-up (ie, jogging, trunk twists, jumping jacks) }\end{array}$ \\
\hline Functional activities & Unspecified exercises for the lower and upper extremities \\
\hline
\end{tabular}

review. A high GRADE defines a systematic review or meta-analysis consisting of at least two high-quality primary studies. A moderate GRADE defines a review including at least one highquality primary study or at least two moderate-quality primary studies. Low GRADE defines a review on only moderate-quality primary studies and/or inconsistent results in the primary studies. Very low GRADE refers to 'no medium to high quality systematic review identified on this topic'. If the authors of the systematic review did not assess the quality of the primary studies (ie, no risk of bias assessment was conducted), they were classified as 'no evidence from systematic review' and the GRADE system was not applied.

\section{Data extraction and analysis}

Two reviewers (RB and $\mathrm{BF}$ ) used a standardised data extraction form as part of the established umbrella review protocol to collect data from the included reviews. ${ }^{19} \mathrm{~A}$ third reviewer (NAM) was consulted when any ambiguity arose during this process. All data were stored and managed in Microsoft Excel 2010.

Injury incidences/rates were analysed separately for five lower extremity injury categories: (1) lower extremity injuries; (2) groin injuries; (3) knee injuries; (4) ACL injuries; and (5) ankle injuries. This categorisation was defined based on the terms mainly used to describe lower extremity injuries in the included systematic reviews/meta-analyses and primary studies. A detailed description of each injury category is listed in table 1.

We defined eight exercise element categories according to the common terms found (table 1): (1) strength; (2) agility; (3) plyometric; (4) balance; (5) stretching; (6) technique; (7) warm-up; and (8) functional activities. Terms $1-5$ were previously adopted from one of the included meta-analyses that tested the effectiveness of each exercise component on ACL injury prevention. ${ }^{15}$ Terms 6-8 were included because they represent frequent exercise concepts. Term 6 , technique, encompassed a correct lower extremity alignment technique while performing demanding weight-bearing tasks (eg, single-leg jumps with a focus on leg 


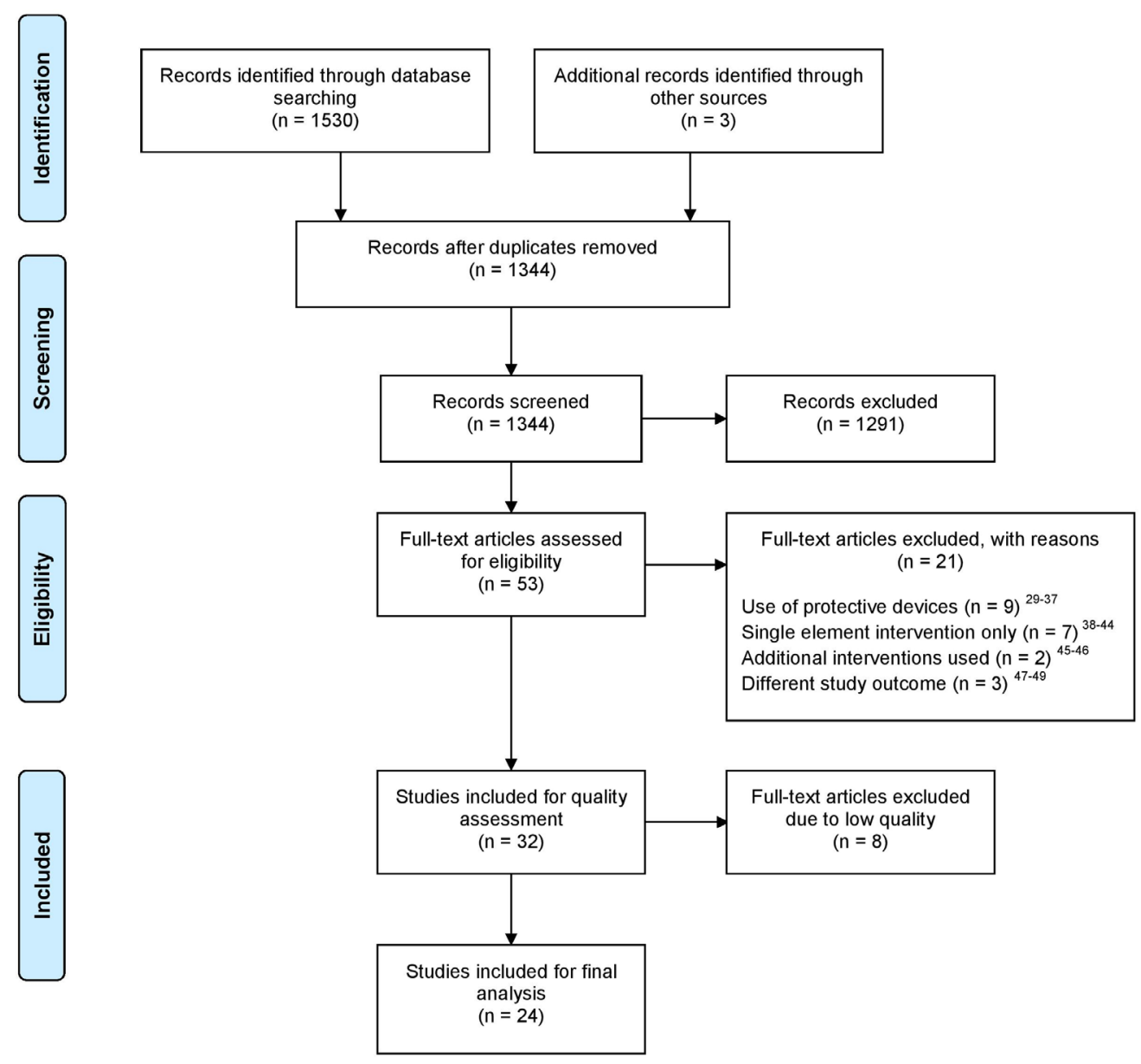

Figure 1 Flow chart of the study selection process.

alignment; jumping and landing techniques; neuromuscular control during landing). ${ }^{24-27}$ Term 7 , warm-up, included aerobic exercises, muscle activation or non-specific basic warm-up exercises such as jogging, trunk twists and jumping jacks. Term 8, functional activities, comprised all non-specific exercise elements for lower and upper extremities as part of the injury prevention programmes found in the studies included in this umbrella review.

Characteristics of the selected systematic reviews/meta-analyses including the AMSTAR and GRADE scores, number of participants, combination of exercise elements, heterogeneity between primary studies $\left(\mathrm{I}^{2}\right)$ as well as results, findings and authors' conclusions are presented in online e-Supplement 1. Within each review/meta-analysis one $e^{28}$ to ten $^{11}$ different combinations of exercise elements were presented.

A summary of the effectiveness of exercise element combinations was made for each injury category, including the mean methodological quality (summary of AMSTAR scores divided by the number of systematic reviews including the exercise element combinations to strengthen the overall results) and overall results. We used a traffic light system to visually summarise the effectiveness of each exercise element combination in reducing the injury incidence/rate per injury category. A green light was set for studies with effective overall results (ie, agreement on the effectiveness of exercise element combinations). An orange light was indicative of studies with inconsistent overall results (ie, disagreement on the effectiveness of exercise element combinations), and a red light of ineffective overall results (ie, agreement on the ineffectiveness of exercise element combinations). ${ }^{19}$

\section{RESULTS}

Our database search identified a total of 1530 records with three additional studies found by our content expert (MB) (figure 1). After duplicates were removed, 1344 records were screened for titles and abstracts. A further 1291 studies were excluded, mainly because the study outcome did not match the one defined at the outset of our review. Of 53 full-text articles evaluated, 21 systematic reviews were excluded for various reasons (figure 1: Eligibility). ${ }^{29-49}$ The 32 remaining systematic reviews were evaluated for methodological quality.

\section{Methodological quality evaluation}

The overall methodological quality of the 32 included reviews is summarised in figure 2. Eight reviews had a total AMSTAR score of $\leq 3$ and were excluded. ${ }^{50-57}$ For the remaining 24 reviews, ${ }^{6-11}$ 13-17 2428 58-70 the following AMSTAR criteria were under-reported: using the status of publication as an inclusion criterion $^{112956-586164}$; providing an a priori design ${ }^{6121764}$; listing all included and excluded primary studies ${ }^{9} 1017$; and stating a conflict of interest. ${ }^{30}$ The majority $(n=17)$ of the 24 included systematic reviews were based on high-quality primary studies (ie, high GRADE) for the outcome of lower extremity, knee, ACL and ankle injuries. Two systematic reviews were of moderate 


\section{$\varpi$ yes $₫$ no $\square$ not applicable $₫$ can't answer}

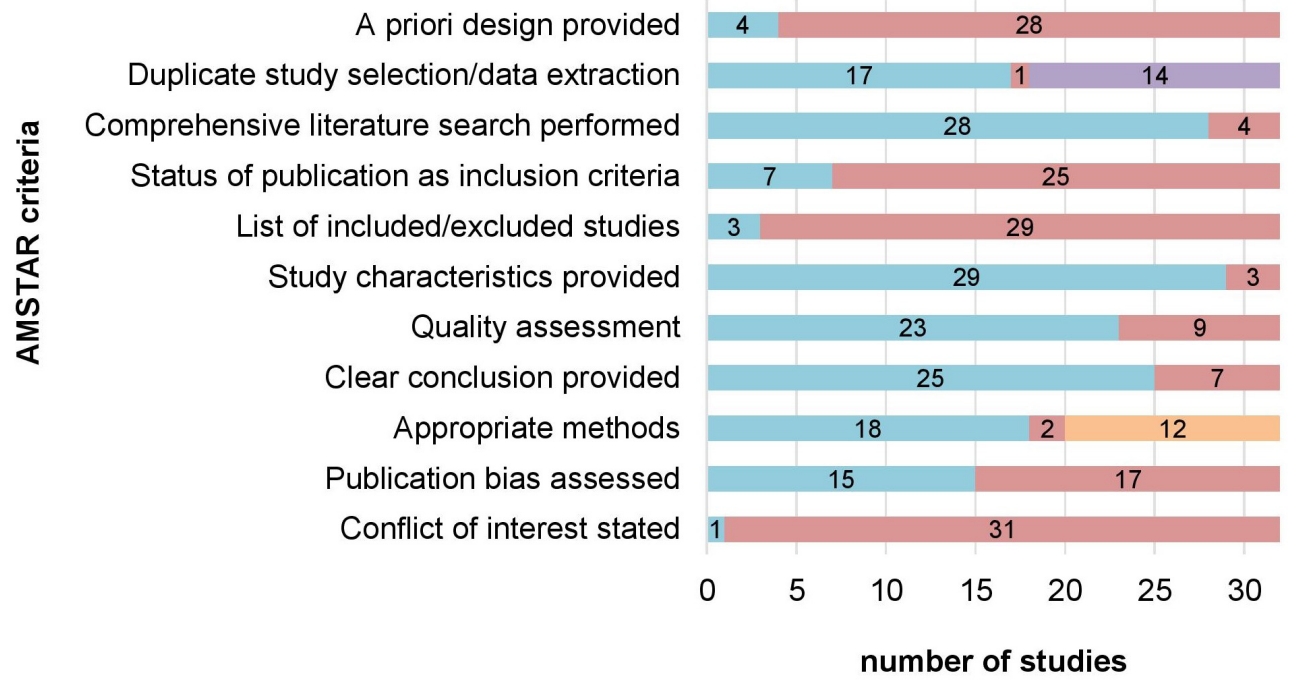

Figure 2 Overall results of the Assessing the Methodological Quality of Systematic Reviews (AMSTAR) checklist ( $\mathrm{n=32}$ ).

GRADE regarding the outcome of ACL injuries ${ }^{24} 68$ and four systematic reviews were of low GRADE regarding the outcome of lower extremity, groin and ACL injuries ${ }^{6136467}$; one systematic review did not assess the quality of the primary studies regarding the outcome of ACL injuries. ${ }^{16}$

\section{Effectiveness of exercise element combinations}

Twenty-six primary studies were included in the analysed systematic reviews.

Ten systematic reviews evaluated eight different exercise element combinations, of which three exercise element combinations were effective in reducing the lower extremity injury incidence/rate (table 2). These effective injury prevention programmes encompassed three different combinations: strength, plyometric, balance, stretching, warm-up; strength, agility, plyometric, balance; and the combination of balance, stretching and warm-up exercises.

For the groin, there were no effective exercise element combinations identified in five systematic reviews (table 2).

Eight systematic reviews reported two combinations of exercise elements as effective in preventing knee injuries (table 2). These effective injury prevention programmes encompassed two different exercise combinations: strength, agility, balance, stretching, technique; and strength, agility, balance, warm-up.

From a total of 10 exercise element combinations focused on reducing ACL injuries, two different exercise combinations were considered effective: strength, plyometric, balance, stretching, warm-up; and strength, agility, balance, warm-up (table 2).

Four combinations of exercise elements were effective in preventing ankle injuries (table 2); these injury prevention programmes included the exercise elements of strength, agility, plyometrics, balance, stretching, technique and warm-up.

Overall, there were 11 combinations of exercise elements that were effective in reducing the injury incidences/rates. Strength and balance exercises were included in 10 effective injury prevention programmes. For lower extremity injuries, balance exercises were included in all three effective injury prevention programmes. Strength, plyometrics, stretching and warm-up exercises were included in two programmes. For knee injuries, strength, balance and agility exercises were included in all three effective injury prevention programmes. Stretching, technique and warm-up exercises were included in two programmes. For ACL injuries, the two effective injury prevention programmes included strength, balance and warm-up exercises. Strength was included in all four effective ankle injury prevention programmes. Balance, agility and stretching exercises were included in three effective ankle injury prevention programmes.

\section{DISCUSSION}

Based on 24 moderate to high-quality systematic reviews and meta-analyses, we found that multicomponent exercise interventions were effective in reducing the injury incidence/rate of lower extremity, knee, ACL and ankle injuries, but not of groin injuries. The most frequent elements of a neuromuscular training programme were a combination of strength and balance exercises.

Several meta-analyses included in this umbrella review showed a beneficial effect of multicomponent exercise programmes for different outcomes (ie, lower extremity, knee, ACL and ankle injuries). ${ }^{10-17}$ The combination of strength and balance exercises enhanced the effect of an injury prevention programme. ${ }^{17}$ Strengthening and proximal control exercises (eg, exercises involving segments proximal to the knee joint) were associated with a reduction in ACL injuries. ${ }^{14}$ On the other hand, injury prevention programmes including balance exercises compared with programmes without balance exercises did not reveal any additional effect in reducing ACL injuries. ${ }^{14} 16$ However, the authors of the systematic reviews did claim the importance of balance exercises in combination with other types of exercises for reducing ACL injuries. ${ }^{14} 16$

In contrast to strength and balance exercises, the exercise components stretching, agility, plyometrics and technique were less frequent in programmes aimed at reducing lower extremity, knee, ACL and ankle injury incidence/rate. According to a meta-analysis included in this umbrella review, stretching added no beneficial effect in decreasing sports injuries. ${ }^{17}$ Several other studies ${ }^{31-34} 7172$ also found limited evidence to support the benefits of stretching before or after training for injury prevention. Stretching increases flexibility, ${ }^{73}$ which is an important quality in specific team sports and playing positions (eg, an ice hockey goalkeeper needs more hip flexibility compared with a field player). Yet higher flexibility 


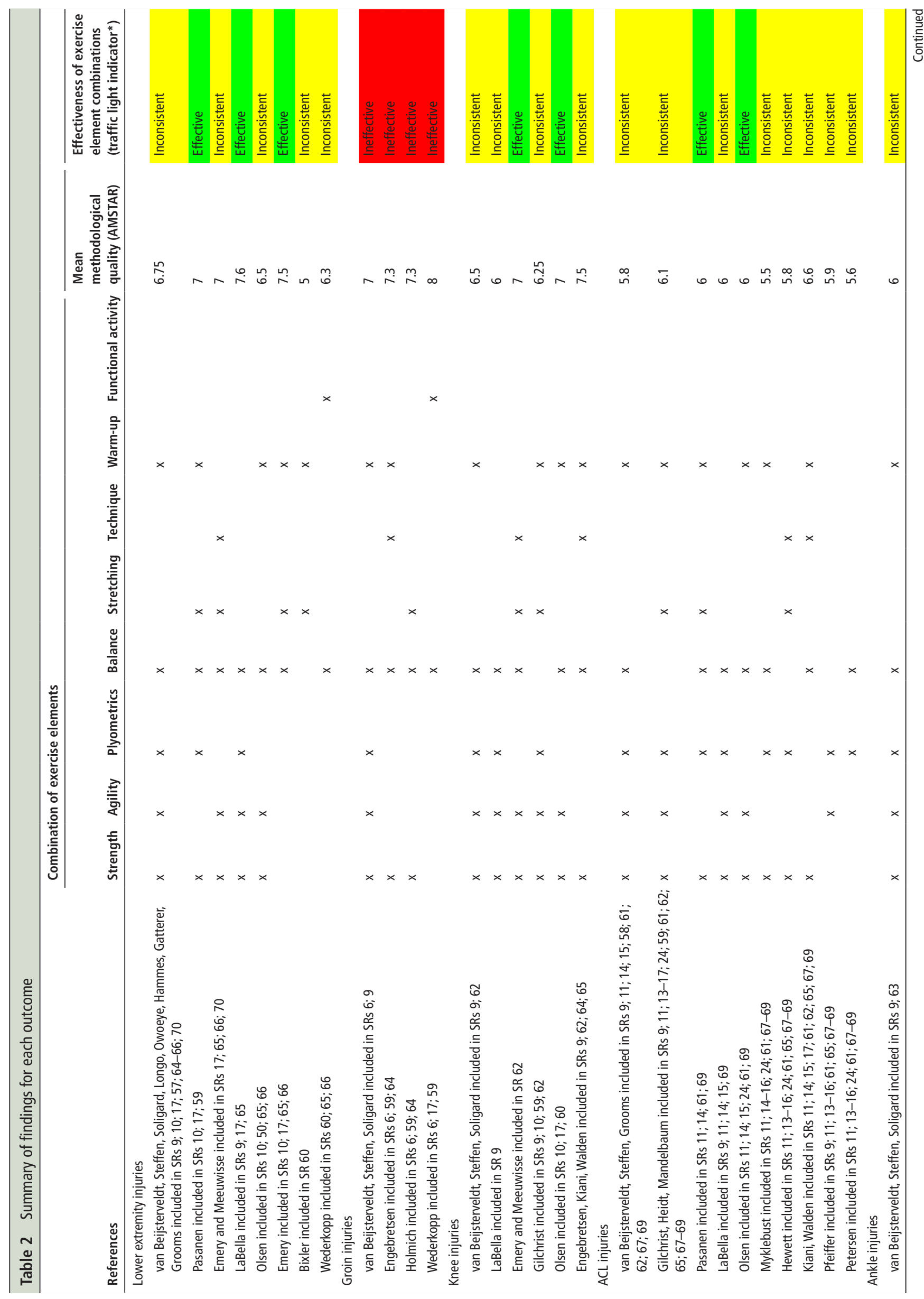


was not associated with a lower risk of injuries. ${ }^{71}$ Thus, the component stretching may not add much additional benefit to a lower extremity injury prevention programme.

Our finding of no beneficial effect of prevention programmes with and without plyometric exercises on ACL injuries supports previous research. ${ }^{14}$ However, this area is not unanimous, and it is possible that plyometric exercises may be effective for ACL injury prevention.

No subgroup analysis within a meta-analysis to assess the specific effectiveness of agility exercises was conducted. Only one systematic review included in this umbrella review claimed the importance of agility exercises incorporated into a multicomponent injury prevention programme to reduce the risk of ACL injuries in female athletes. ${ }^{24}$ It has been shown that a combination of agility and plyometric exercises contributed to a risk reduction that was associated with knee valgus angles and moments. ${ }^{4}$ A combination of plyometric and agility exercises might therefore protect the knee joint during dynamic movements ${ }^{14}$ and be beneficial in reducing ACL injuries when included in injury prevention programmes.

Technique exercises described in the included reviews focused on leg alignment during landing manoeuvers following a jump. Technique exercises may be less important because jumping was not a usual action in all the team sports considered in this umbrella review (ie, floorball and soccer). Nevertheless, landing technique exercises have been successfully applied to decrease knee varus/ valgus moments ${ }^{27}$; various studies used visual feedback and/or education on dangerous knee postures to modify landing manoeuvres. $^{25-277475}$ However, the authors might not have classified that as an exercise itself, which might lead to a reporting bias of technique exercises, and is therefore considered as less important in this umbrella review.

There are two types of injuries that require differentiation based on their occurrence: traumatic and overuse. All articles considered in this umbrella review focused on traumatic injuries. Therefore, making any conclusions about the effects of injury prevention programmes on reducing the rate of overuse injuries is not justified. It was previously reported that groin injuries are mainly overuse in origin ${ }^{5}$ and represent a serious problem in many sports. ${ }^{7677}$ However, a recent meta-analysis, included in our umbrella review, ${ }^{6}$ reported a total number of groin injuries that was very low in comparison to other injury types. Despite the relatively large sample size, there were only traumatic injuries examined, which may indicate a reporting bias. It is important to systematically assess all overuse injuries in addition to traumatic injuries in future primary studies. Detailed prevalence data of overuse injuries may support the development of overuse-specific prevention programmes.

\section{Strengths and limitations}

Our umbrella review ensured a high-level synthesis of the evidence $^{18}$ regarding injury prevention programmes in team-sport athletes and allowed to identify the most frequent exercise combinations for lower extremity injury prevention.

Due to study participant heterogeneity, it was not possible to stratify the main findings by age, sex, type of sports and level of play. One problem inherent in a study of this kind is the definition of outcomes assessed in the reviews. For example, various reviews used the outcome knee injuries, whereas others specifically used the outcome ACL injuries. We presume that some reviews with the outcome knee injuries might also have included ACL injuries. However, this did not influence the outcome of this umbrella review because ACL injuries were considered as knee ligament injuries. Some reviews used different exercise descriptions or 
poorly reported the type of exercise element in the prevention programmes. This may have led to a misclassification of exercise elements. Various authors classified jumping as plyometrics, which can also be interpreted as landing technique exercises. We also speculate that participants in the primary studies may have been trained to focus on leg alignment during landing, while alignment during landing was not considered as an exercise itself. Therefore, there is a risk for reporting bias.

Many of the reviews included in our umbrella review included the same primary studies and concluded on the same available data, which reveals a large overlap among published systematic reviews and meta-analyses. What appears to be a large number of primary studies and evidence could partly be due to an overpublication of systematic reviews and meta-analyses on the topic of injury prevention. We encountered some reporting bias within the reviews and primary studies regarding a detailed description of the types of intervention and degree of compliance. Therefore, we could not formulate recommendations for specific exercise modalities (eg, contraction type, load or execution speed when performing strength exercises). A systematic documentation of prevention programmes including the target group, a detailed exercise description using the frequency, intensity/type, time principles, and description of delivery agents should be considered in future studies to enhance generalisability and reproducibility. ${ }^{78}$ Particularly for groin injuries, improved reporting of prevalence data is required. More high-quality intervention studies are also needed to accurately evaluate the effectiveness of multicomponent programmes for specifically preventing traumatic as well as overuse injuries.

\section{CONCLUSIONS}

Multicomponent lower extremity exercise programmes were effective in preventing lower extremity, knee, ACL and ankle injuries in the team sports of soccer, floorball, Australian and American football, basketball, handball and volleyball for all age levels and sex.

\section{What is already known}

- There is a large number of systematic reviews available on the effectiveness of injury prevention programmes for the lower extremity in team-sport athletes.

- Injury prevention programmes reduce the risk of traumatic injuries of the lower extremity in athletes.

- Multicomponent prevention programmes are more effective compared with single element prevention programmes.

\section{What are the new findings}

- In 10 of 11 effective injury prevention programmes regarding lower extremity, knee, ACL and ankle injuries, strength and balance are considered the most important exercise elements for team-sport athletes.

- Agility and plyometric exercises might be beneficial in reducing the $\mathrm{ACL}$ injury incidence/rate when performed in combination with strength and balance exercises as part of an injury prevention programme.

- Due to the heterogeneity of methodological descriptions in the reviews, it is impossible to draw conclusions about the specific intervention(s) for each exercise category as well as the frequency and intensity of an injury prevention programme.
Muscle strength and balance exercises seem to be the most frequent components in a lower extremity injury prevention programme.

Contributors RB: conception and design, literature search, methodological quality assessment, data extraction, data analysis, data interpretation, drafting of the manuscript, revision/editing of the manuscript, final approval of the manuscript, agreement to be accountable for all aspects of the work. BF: data extraction, critical revision of the manuscript, final approval of the manuscript, agreement to be accountable for all aspects of the work. NCC and MB: literature search, critical revision of the manuscript, final approval of the manuscript, agreement to be accountable for all aspects of the work. NAM: conception and design, disagreement solving, critical revising of the manuscript, final approval of the manuscript, agreement to be accountable for all aspects of the work. KN: conception and design, methodological quality assessment, data analysis, data interpretation, critical revision of the manuscript, final approval of the manuscript, agreement to be accountable for all aspects of the work.

Funding The authors have not declared a specific grant for this research from any funding agency in the public, commercial or not-for-profit sectors.

Competing interests None declared.

Patient consent Not required.

Provenance and peer review Not commissioned; externally peer reviewed.

\section{REFERENCES}

1 Sheu Y, Chen LH, Hedegaard H. Sports- and recreation-related injury episodes in the United States, 2011-2014. Natl Health Stat Report 2016:1-12.

2 EuroSafe: Injuries in the European Union. Summary on injury statistics 2012-2014. http://www.bridge-health.eu/sites/default/files/EuropeSafe_Master_R4_SinglePage_ 12102016\%20\%281\%29.pdf (accessed 8 Nov 2017).

3 Ter Stege MH, Dallinga JM, Benjaminse A, et al. Effect of interventions on potential, modifiable risk factors for knee injury in team ball sports: a systematic review. Sports Med 2014:44:1403-26.

4 Hootman JM, Dick R, Agel J. Epidemiology of collegiate injuries for 15 sports: summary and recommendations for injury prevention initiatives. J Athl Train 2007:42:311-9.

5 Pettersson M, Lorentzon R. Ice hockey injuries: a 4-year prospective study of a Swedish élite ice hockey team. Br J Sports Med 1993;27:251-4.

6 Esteve E, Rathleff MS, Bagur-Calafat $C$, et al. Prevention of groin injuries in sports: a systematic review with meta-analysis of randomised controlled trials. $\mathrm{Br} J$ Sports Med 2015:49:785-91.

7 Meeuwisse WH. Assessing causation in sport injury: a multifactorial model. Clin J Sport Med 1994;4:166-70.

8 Bahr R, Holme I. Risk factors for sports injuries--a methodological approach. Br J Sports Med 2003;37:384-92.

9 Herman K, Barton C, Malliaras P, et al. The effectiveness of neuromuscular warm-up strategies, that require no additional equipment, for preventing lower limb injuries during sports participation: a systematic review. BMC Med 2012;10:75.

10 Hübscher M, Zech A, Pfeifer K, et al. Neuromuscular training for sports injury prevention: a systematic review. Med Sci Sports Exerc 2010;42:413-21.

11 Myer GD, Sugimoto D, Thomas S, et al. The influence of age on the effectiveness of neuromuscular training to reduce anterior cruciate ligament injury in female athletes: a meta-analysis. Am J Sports Med 2013:41:203-15.

12 Rössler R, Donath L, Verhagen E, et al. Exercise-based injury prevention in child and adolescent sport: a systematic review and meta-analysis. Sports Medicine 2014;44:1733-48.

13 Sadoghi P, von Keudell A, Vavken P. Effectiveness of anterior cruciate ligament injury prevention training programs. J Bone Joint Surg Am 2012;94:769-76.

14 Sugimoto D, Myer GD, Foss KD, et al. Specific exercise effects of preventive neuromuscular training intervention on anterior cruciate ligament injury risk reduction in young females: meta-analysis and subgroup analysis. Br J Sports Med 2015;49:282-9.

15 Taylor JB, Waxman JP, Richter SJ, et al. Evaluation of the effectiveness of anterior cruciate ligament injury prevention programme training components: a systematic review and meta-analysis. Br J Sports Med 2015;49:79-87.

$16 \mathrm{Yoo} \mathrm{JH}$, Lim BO, Ha M, et al. A meta-analysis of the effect of neuromuscular training on the prevention of the anterior cruciate ligament injury in female athletes. Knee Surg Sports Traumatol Arthrosc 2010;18:824-30.

17 Lauersen JB, Bertelsen DM, Andersen LB. The effectiveness of exercise interventions to prevent sports injuries: a systematic review and meta-analysis of randomised controlled trials. Br J Sports Med 2014;48:871-7.

18 Ioannidis J. Next-generation systematic reviews: prospective meta-analysis, individuallevel data, networks and umbrella reviews. Br J Sports Med 2017;51:1456-8.

19 Aromataris E, Fernandez R, Godfrey CM, et al. Summarizing systematic reviews: methodological development, conduct and reporting of an umbrella review approach. Int J Evid Based Healthc 2015;13:132-40. 
20 Sharif MO, Janjua-Sharif FN, Sharif FN, et al. Systematic reviews explained: AMSTAR-how to tell the good from the bad and the ugly. Oral Health Dent Manag 2013;12:9-16.

21 Miller SA, Forrest JL. Enhancing your practice through evidence-based decision making: PICO, learning how to ask good questions. Journal of Evidence Based Dental Practice 2001;1:136-41.

22 Shea BJ, Hamel C, Wells GA, et al. AMSTAR is a reliable and valid measurement tool to assess the methodological quality of systematic reviews. J Clin Epidemiol 2009;62:1013-20

23 Moe RH, Haavardsholm EA, Christie A, et al. Effectiveness of nonpharmacological and nonsurgical interventions for hip osteoarthritis: an umbrella review of high-quality systematic reviews. Phys Ther 2007;87:1716-27.

24 Grindstaff TL, Hammill RR, Tuzson AE, et al. Neuromuscular control training programs and noncontact anterior cruciate ligament injury rates in female athletes: a numbersneeded-to-treat analysis. J Ath/ Train 2006;41:450-6.

25 Oñate JA, Guskiewicz KM, Marshall SW, et al. Instruction of jump-landing technique using videotape feedback: altering lower extremity motion patterns. Am J Sports Med 2005;33:831-42.

26 Milner CE, Fairbrother JT, Srivatsan A, et al. Simple verbal instruction improves knee biomechanics during landing in female athletes. Knee 2012;19:399-403.

27 Myer GD, Ford KR, Hewett TE. Rationale and clinical techniques for anterior cruciate ligament injury prevention among female athletes. J Ath/ Train 2004;39:352-64.

28 Al Attar WS, Soomro N, Pappas E, et al. How effective are F-marc injury prevention programs for soccer players? A systematic review and meta-analysis. Sports Med 2016;46:205-17.

29 Sugimoto D, Myer GD, Bush HM, et al. Compliance with neuromuscular training and anterior cruciate ligament injury risk reduction in female athletes: a meta-analysis. J Athl Train 2012:47:714-23.

30 Sugimoto D, Myer GD, Foss KD, et al. Dosage effects of neuromuscular training intervention to reduce anterior cruciate ligament injuries in female athletes: metaand sub-group analyses. Sports Med 2014;44:551-62.

31 Lewis J. A systematic literature review of the relationship between stretching and athletic injury prevention. Orthop Nurs 2014;33:312-20.

32 Small K, Mc Naughton L, Matthews M. A systematic review into the efficacy of static stretching as part of a warm-up for the prevention of exercise-related injury. Res Sports Med 2008;16:213-31.

33 Thacker SB, Gilchrist J, Stroup DF, et al. The impact of stretching on sports injury risk: a systematic review of the literature. Med Sci Sports Exerc 2004;36:371-8.

34 Weldon SM, Hill RH, Hrh WSM. The efficacy of stretching for prevention of exerciserelated injury: a systematic review of the literature. Man Ther 2003;8:141-50.

35 Aaltonen $\mathrm{S}$, Karjalainen $\mathrm{H}$, Heinonen $\mathrm{A}$, et al. Prevention of sports injuries: systematic review of randomized controlled trials. Arch Intern Med 2007;167:1585-92.

36 Abernethy L, Bleakley C. Strategies to prevent injury in adolescent sport: a systematic review. Br J Sports Med 2007:41:627-38.

37 Grimm NL, Shea KG, Leaver RW, et al. Efficacy and degree of bias in knee injury prevention studies: a systematic review of RCTs. Clin Orthop Relat Res 2013;471:308-16

38 Handoll HH, Rowe BH, Quinn KM, et al. Interventions for preventing ankle ligament injuries. Cochrane Database Syst Rev 2001;3:CD000018.

39 Leppänen M, Aaltonen S, Parkkari J, et al. Interventions to prevent sports related injuries: a systematic review and meta-analysis of randomised controlled trials. Sports Med 2014;44:473-86.

40 McGuine T. Sports injuries in high school athletes: a review of injury-risk and injuryprevention research. Clin J Sport Med 2006;16:488-99.

41 Thacker SB, Stroup DF, Branche CM, et al. Prevention of knee injuries in sports. A systematic review of the literature. J Sports Med Phys Fitness 2003;43:165.

42 Verhagen EA, van Mechelen W, de Vente W. The effect of preventive measures on the incidence of ankle sprains. Clin J Sport Med 2000;10:291-6.

43 Verhagen EA, Bay K. Optimising ankle sprain prevention: a critical review and practical appraisal of the literature. Br J Sports Med 2010;44:1082-8.

44 Goode AP, Reiman MP, Harris L, et al. Eccentric training for prevention of hamstring injuries may depend on intervention compliance: a systematic review and metaanalysis. Br J Sports Med 2015:49:349-56.

45 Hibbert 0 , Cheong K, Grant A, et al. A systematic review of the effectiveness of eccentric strength training in the prevention of hamstring muscle strains in otherwise healthy individuals. N Am J Sports Phys Ther 2008:3:67-81.

46 Schiftan GS, Ross LA, Hahne AJ. The effectiveness of proprioceptive training in preventing ankle sprains in sporting populations: a systematic review and metaanalysis. J Sci Med Sport 2015;18:238-44.

47 Goldman EF, Jones DE. Interventions for preventing hamstring injuries. Cochrane Database Syst Rev 2010;20:CD006782

48 Olsen L, Scanlan A, MacKay M, et al. Strategies for prevention of soccer related injuries: a systematic review. Br J Sports Med 2004;38:89-94.

49 Whittaker JL, Small C, Maffey L, et al. Risk factors for groin injury in sport: an updated systematic review. Br J Sports Med 2015:49:803-9.

50 Barengo NC, Meneses-Echávez JF, Ramírez-Vélez R, et al. The impact of the FIFA 11+ training program on injury prevention in football players: a systematic review. Int J Environ Res Public Health 2014;11:11986-2000.
51 Frisch A, Croisier JL, Urhausen A, et al. Injuries, risk factors and prevention initiatives in youth sport. Br Med Bull 2009;92:95-121.

52 Hewett TE, Myer GD. Reducing knee and anterior cruciate ligament injuries among female athletes. J Knee Surg 2005;18:82-8.

53 Hewett TE, Ford KR, Myer GD. Anterior cruciate ligament injuries in female athletes: Part 2, a meta-analysis of neuromuscular interventions aimed at injury prevention. $A m$ J Sports Med 2006;34:490-8.

54 Kirkendall DT, Junge A, Dvorak J. Prevention of football injuries. Asian J Sports Med 2010;1:81-92.

55 Michaelidis M, Koumantakis GA. Effects of knee injury primary prevention programs on anterior cruciate ligament injury rates in female athletes in different sports: a systematic review. Phys Ther Sport 2014;15:200-10.

56 Noyes FR, Barber-Westin SD. Neuromuscular retraining intervention programs: do they reduce noncontact anterior cruciate ligament injury rates in adolescent female athletes? Arthroscopy 2014;30:245-55.

57 Noyes FR, Barber Westin SD. Anterior cruciate ligament injury prevention training in female athletes: a systematic review of injury reduction and results of athletic performance tests. Sports Health 2012;4:36-46.

58 Alentorn-Geli E, Mendiguchía J, Samuelsson K, et al. Prevention of non-contact anterior cruciate ligament injuries in sports. Part II: systematic review of the effectiveness of prevention programmes in male athletes. Knee Surg Sports Traumatol Arthrosc 2014;22:16-25.

59 Andrew N, Gabbe BJ, Cook J, et al. Could targeted exercise programmes prevent lower limb injury in community Australian football? Sports Med 2013;43:751-63.

60 Fradkin AJ, Gabbe BJ, Cameron PA. Does warming up prevent injury in sport? The evidence from randomised controlled trials? J Sci Med Sport 2006;9:214-20.

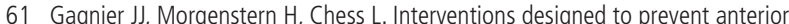
cruciate ligament injuries in adolescents and adults: a systematic review and metaanalysis. Am J Sports Med 2013;41:1952-62.

62 Grimm NL, Jacobs JC, Kim J, et al. Anterior cruciate ligament and knee injury prevention programs for soccer players: a systematic review and meta-analysis. Am J Sports Med 2015;43:2049-56.

63 Grimm NL, Jacobs JC, Kim J, et al. Ankle injury prevention programs for soccer athletes are protective: a level-i meta-analysis. J Bone Joint Surg Am 2016:98:1436-43

64 Porter T, Rushton A. The efficacy of exercise in preventing injury in adult male football: a systematic review of randomised controlled trials. Sports Med Open 2015;1:4

65 Rössler R, Donath L, Verhagen E, et al. Exercise-based injury prevention in child and adolescent sport: a systematic review and meta-analysis. Sports Med 2014;44:1733-48.

66 Soomro N, Sanders R, Hackett D, et al. The efficacy of injury prevention programs in adolescent team sports: a meta-analysis. Am J Sports Med 2016:44:2415-24.

67 Stevenson JH, Beattie CS, Schwartz JB, et al. Assessing the effectiveness of neuromuscular training programs in reducing the incidence of anterior cruciate ligament injuries in female athletes: a systematic review. Am J Sports Med 2015;43:482-90.

68 Stojanovic MD, Ostojic SM. Preventing ACL injuries in team-sport athletes: a systematic review of training interventions. Res Sports Med 2012;20:223-38.

69 Sugimoto D, Myer GD, McKeon JM, et al. Evaluation of the effectiveness of neuromuscular training to reduce anterior cruciate ligament injury in female athletes: a critical review of relative risk reduction and numbers-needed-to-treat analyses. $\mathrm{Br} J$ Sports Med 2012;46:979-88.

70 van Beiisterveldt AM, van der Horst N, van de Port IG, et al. How effective are exercise-based injury prevention programmes for soccer players? A systematic review. Sports Med 2013:43:257-65.

71 Shrier I. Stretching before exercise does not reduce the risk of local muscle injury: a critical review of the clinical and basic science literature. Clin J Sport Med 1999;9:221-7

72 Witvrouw E, Mahieu N, Danneels L, et al. Stretching and injury prevention: an obscure relationship. Sports Med 2004;34:443-9.

73 Bandy WD, Irion JM, Briggler M. The effect of time and frequency of static stretching on flexibility of the hamstring muscles. Phys Ther 1997;77:1090-6.

74 Hewett TE, Myer GD, Ford KR, et al. Mechanisms, prediction, and prevention of $\mathrm{ACL}$ injuries: Cut risk with three sharpened and validated tools. J Orthop Res 2016:34:1843-55.

75 Sugimoto D, Alentorn-Geli E, Mendiguchía J, et al. Biomechanical and neuromuscular characteristics of male athletes: implications for the development of anterior cruciate ligament injury prevention programs. Sports Med 2015;45:809-22.

76 Bahr R. No injuries, but plenty of pain? On the methodology for recording overuse symptoms in sports. Br J Sports Med 2009;43:966-72.

77 Clarsen B, Myklebust G, Bahr R. Development and validation of a new method for the registration of overuse injuries in sports injury epidemiology: the Oslo Sports Trauma Research Centre (OSTRC) overuse injury questionnaire. Br J Sports Med 2013;47:495-502.

78 O'Brien J, Donaldson A, Barbery G, et al. The three must-do's of intervention reporting: enhancing sports injury prevention research. Br J Sports Med 2014;48:1267-9. 